\title{
Macrodontia and Dens Invaginatus - Review of the literature and a case report
}

SADJ March 2021, Vol. 76 No. 2 p91 - p95

PJ van der Vyver ${ }^{1}$, N Potgieter ${ }^{2}$, N Moelich ${ }^{3}$, Z Vally $^{4}$

\begin{abstract}
Disturbances in histodifferentiation and morphodifferentiation may include genetic or environmental factors. These disturbances often lead to dental anomalies. This paper reviews the aetiology, clinical and radiographic appearance, diagnosis and treatment options for macrodontia and dens invaginatus respectively.
\end{abstract}

A rare case is presented in which the two anomalies occurred directly next to each other in the anterior dentition of a young boy. The diagnostic process and management are reported with a detailed explanation of the use of modern diagnostic aids and equipment.

The procedure of apexification is also described in detail as both anterior teeth were still immature when they turned necrotic. A 2-year follow up reported the successful treatment resolution of infection and associated symptoms, as well as restoration of function and aesthetics.

\section{Keywords}

Macrodontia, Dens Invaginatus, Apexification

\section{INTRODUCTION}

The aetiology of many dental anomalies remains unknown. Tooth development starts in utero and during embryonic development, when neural crest cells undergo epithelialmesenchymal transformation. Cells migrate and reorganize away from the neural tube. In the head area, tissue derived

\section{Author affiliations:}

1. Petrus J van der Vyver: BChD, PG Dip Dent (Endo), PG Dip Dent (Aesthet Dent), MSc, PhD (Pret), Department of Odontology, School of Dentistry, University of Pretoria, Pretoria, South Africa. ORCID Number: 0000-0003-1951-6042

2. Nicoline Potgieter: BChD (UP), PG Dip Dent: Endodontics (UP), PG Dip Paedodontics (UWC), MSc Dent (UP), Head of Division of Paediatric Dentistry, Department of Odontology, School of Dentistry, Faculty of Health Sciences, Pretoria, South-Africa ORCID Number: 0000-0003-4061-3322

3. Nadine Moelich: BchD (UP), PG Dip: Paedodontics (UP), MSc.Dent (UP), Department of Odontology, School of Dentistry, University of Pretoria, South Africa.

4. Zunaid Vally: BDS, MDent (Prosthodontics) (Wits), Department of Odontology, School of Dentistry, University of Pretoria, South Africa.

ORCID Number: 0000-0002-2718-4706

Corresponding author: Nicoline Potgieter

Department of Odontology, School of Dentistry, Faculty of Health

Sciences, PO Box 1266, Pretoria 0001, South-Africa.

Email: nicoline.potgieter@up.ac.za

Author contributions:

1. Petrus $\mathbf{J}$ van der Vyver: First author, clinical work, write up, editing $-40 \%$

2. Nicoline Potgieter: Second author, write up and editing, submission - $30 \%$

3. Nadine Moelich: Third author, contributed to write up - 15\%

4. Zunaid Vally: Fourth author, contributed to editing - $15 \%$ from the mesoderm is referred to as ectomesenchyme with neuroectoderm as the origin. From a dental perspective, proper migration of neural crest cells is imperative for the development of the face and teeth. ${ }^{1}$

In addition to the enamel and certain parts of the cementum, neural crest cells are responsible for the formation of all tooth structures. Within the dentinal lamina that has formed, proliferation is constantly occurring, leading to the formation of epithelial buds in the ectomesenchyme. Next, the primary dentition is produced, followed by subsequent permanent dentition. ${ }^{1,2}$

Tooth formation is a complex process with ongoing histodifferentiation and morphodifferentiation. Cells are dependent on each other for this differentiation, and there is space for deviation, leading to disturbance of the tooth germ. Disturbances may include genetic or environmental factors ${ }^{3}$ and result in conditions such as microdontia, macrodontia, dens invaginatus, dens evaginatus, Talon's cusp, taurodontism, fusion, gemination, concrescence, dilacerations, enamel pearls and supernumerary teeth. ${ }^{2}$

\section{MACRODONTIA}

Macrodontia, also known as megadontia or megalodontia, refers to teeth that are physically larger than normal and could clinically be confused with other conditions such as fusion (two separate tooth germs fusing to form one tooth) and gemination (two teeth that form from one follicle but are not separated)..$^{2,4}$

Three different types of macrodontia can be found: true generalized, where many teeth in the mouth are affected (very rare); relative generalized, where all the teeth are affected, and the teeth can either be of normal size in a very small jaw creating the illusion of macrodontia or all the teeth may be slightly enlarged; isolated macrodontia, where only a single tooth is affected (very rare). ${ }^{5}$

The prevalence of macrodontia in permanent dentition is $0.03 \%$ to $1.9 \%$, with a higher incidence in males. ${ }^{3}$ Macrodontia in the anterior region poses an aesthetic problem for patients, leading to crowding, plaque accumulation, interdigitation and overjet reduction. ${ }^{6,7}$

Treatment is mostly limited to aesthetic desires and may pose challenges during restoration, requiring a multidisciplinary approach, including possible endodontic, periodontic or orthodontic treatment. ${ }^{6-8}$ Restoring these teeth is imperative to address the patients' emotional wellbeing. ${ }^{8}$ Teeth with macrodontia have wide pulp chambers, limiting 
the opportunity to simply grind these teeth smaller because root canal therapy would be imperative. ${ }^{8}$

\section{DENS INVAGINATUS (DI)}

$\mathrm{Dl}$ is a developmental anomaly presenting with complex morphological variations. This anomaly has also been referred to as 'dens in dente', 'dilated composite odontome', 'gestant anomaly' or, simply, an enamel-lined tract.9,10 DI is the preferred term and has been described as deep infolding of the enamel organ into the dental papilla during tooth development. ${ }^{11}$ Starting from the foramen coecum or tip of the cusps, it can extend deep into the root, with or without pulp involvement, sometimes even resulting in a second apical foramen. ${ }^{11}$ This anomaly frequently results in early pulp necrosis; therefore managing an open apex can contribute to the complexity of root canal treatment.

Teeth most affected are maxillary lateral incisors with a bilateral occurrence. ${ }^{11-13}$ Possible presentation with other anomalies/malformations include microdontia, macrodontia, hypodontia, oligodontia, taurodontism, germination/ fusion and/or supernumerary teeth. ${ }^{11,14-16}$ The case report in this article demonstrates the coincidence of macrodontia with DI.

The aetiology of DI remains debatable. Theories include buckling of the enamel organ because of growth pressure ${ }^{12}$ or focal failure of the growth of the internal enamel epithelium while the surrounding epithelium continues to proliferate and engulf the static area. ${ }^{17}$ Another theory is that a distortion and subsequent protrusion of a part of the enamel organ that will lead to the formation of an enamellined channel. ${ }^{18}$ The 'twin-theory' suggesting a fusion of two tooth germs, rapid proliferation of the internal enamel epithelium, infection and trauma have all been suggested as possible causes of Dl. ${ }^{19-21}$ Genetic factors cannot be excluded. ${ }^{14}$ Therefore, several theories have been postulated but they might be case specific because no single theory has been proven to apply to all cases.

Clinically, the affected teeth may vary in presentation with an increased crown diameter, incisal notching, hypoplasia at the palatal pit, peg or conical morphology, an exaggerated or bifid cingulum, a talon cusp or a deep foramen coecum. ${ }^{18,22-25}$ However, the absence of significant clinical signs may often leave DI undiagnosed until symptoms arise from caries or pulpal involvement. ${ }^{26}$

An additional $\mathrm{X}$-ray is advised with a horizontal change of 15 degrees in the mesial direction if $\mathrm{DI}$ is suspected. ${ }^{27}$ Radiographically, the pulpal morphology of affected teeth usually appear more complex than normal with an alteration in the pulp outline form and associated periapical lesions. ${ }^{27}$ The shape of the invagination can vary from a narrow fissure to a tear-shaped loop pointing towards the main body of the pulp. ${ }^{28,29}$ The invagination may appear as a radiolucent pocket often, but not always, surrounded by a radiopaque enamel border. ${ }^{27,30}$ When the invagination is completely separate from the pulp with its own opening into the periodontal ligament, it can be described as a 'pseudocanal'. ${ }^{31}$ Two dimensional radiographs may not provide the true extent of the anomaly, and it is advised to utilize cone beam computed tomography (CBCT) as a diagnostic tool.
DI was first classified by Hallet ${ }^{32}$ in 1953, followed by Oehlers ${ }^{18}$ in 1957, and remains the most commonly used classification due to its simplicity. Schulze and Brand ${ }^{33}$ developed a more detailed classification in 1972 that includes invaginations originating not only in the coecum but also at the incisal edge/tip of a crown. This classification also includes dysmorphic root configurations.

According to the literature, Oehlers' radiographic classification is still used more frequently today than any other. ${ }^{18}$ He described three types of DI (Figure 1): Type 1: minor invagination limited to the crown, not extending beyond the cemento-enamel junction; Type II: apical extending invagination not limited to the coronal region but extending beyond the cemento-enamel junction, forming a blind sac inside the root that may or may not communicate with the pulp; Type III: severe apical extension of the invagination into the root and exiting into the periodontium. ${ }^{18}$ Type III can further be divided into Types III a and b. With Type III a, the invagination extends into the root and exits laterally into the periodontal space; pulpal involvement is unlikely. ${ }^{34,35}$ Type III b shows an invagination extending into the root and exiting at the apical foramen into the periodontal space. ${ }^{34,35}$ In rare cases of Type $\mathrm{II} \mathrm{b}$, the invagination can be outlined by cementum. ${ }^{35}$

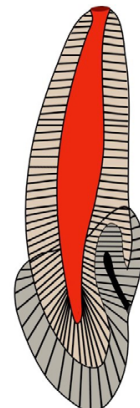

Type I

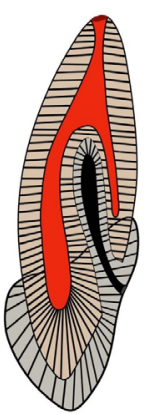

Type II

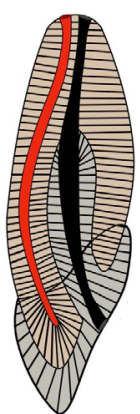

Type III a

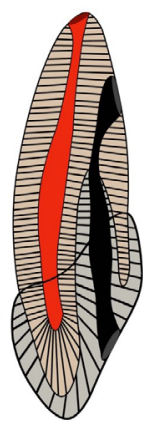

Type III b
Figure 1. Classification of invaginated teeth by Oehlers. ${ }^{18}$

The choice of treatment is dictated by the anatomic complexity of each individual case. This case report demonstrates the coincidence of macrodontia on a maxillary central incisor and a maxillary lateral incisor with Type ॥ dens invaginatus, both with immature root formation. We aimed to report and discuss the unusual finding and treatment of macrodontia and dens invaginatus of per manent maxillary incisors in the dentition of an 11-year-old male patient.

\section{CASE REPORT}

The patient, a healthy 11-year-old male, presented with pain and extreme mobility on his left maxillary central incisor that presented with a macrodontia anomaly (Figure 2).

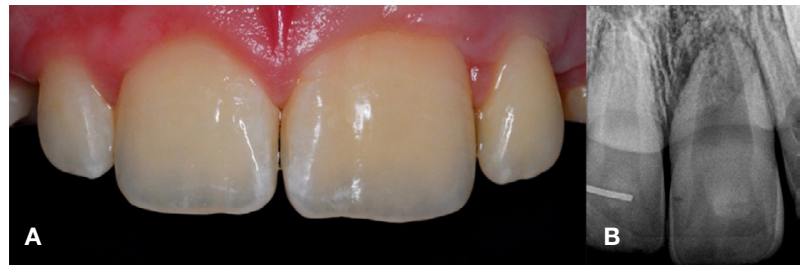

Figure 2. (A) Preoperative clinical photograph of the buccal view of the maxillary central incisors. (B) Intraoral periapical view of the left maxillary central incisor confirming the macrodontia anomaly. 
The tooth did not respond to any vitality testing and a periapical radiograph revealed a very large pulp chamber with evidence of periapical pathology around the immature root of the tooth. Vitality testing was normal for the surrounding incisor teeth. Preoperative CBCT confirmed the evidence of periapical pathology around the root of the left maxillary central incisor, a very large pulp chamber and a wide open apex (Figure 3A-C). Additionally, the left and right lateral incisors presented with dens invaginatus and tested vital at the time. The palatal grooves representing the entrance to the invaginations on the lateral incisor were previously sealed
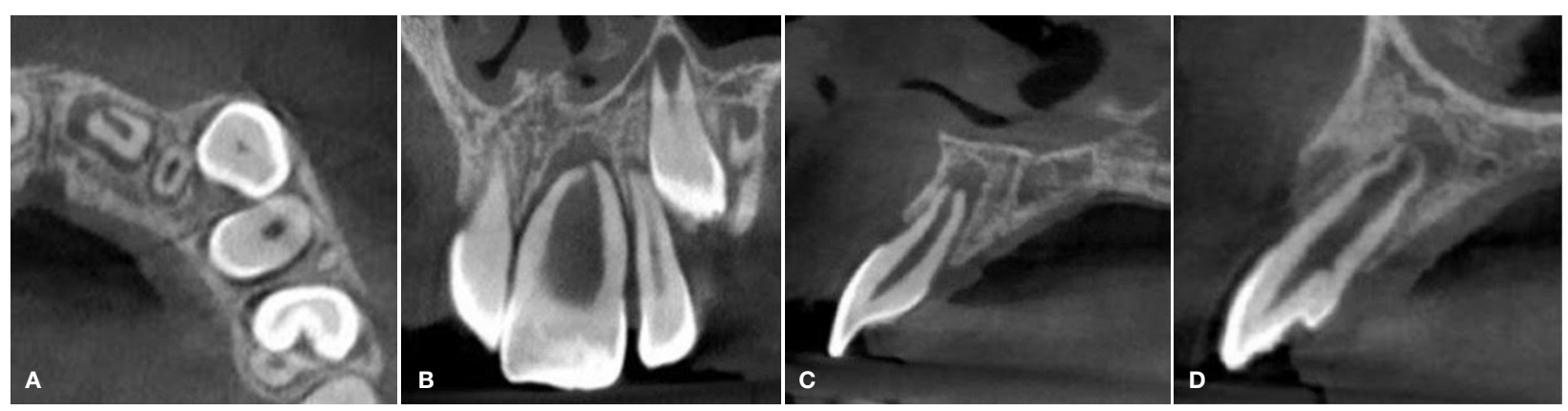

Figure 3. Limited field-of-view CBCT showing: (A) the axial view of the maxillary central incisors demonstrating a periapical lesion around the root tip of the left maxillary central incisor; (B) the coronal view confirming the periapical pathology and incomplete root formation; (C) the sagittal view confirming immature root development with an open apex; and (D) the sagittal view of the vital left lateral incisor presenting with dens invaginatus Type II.
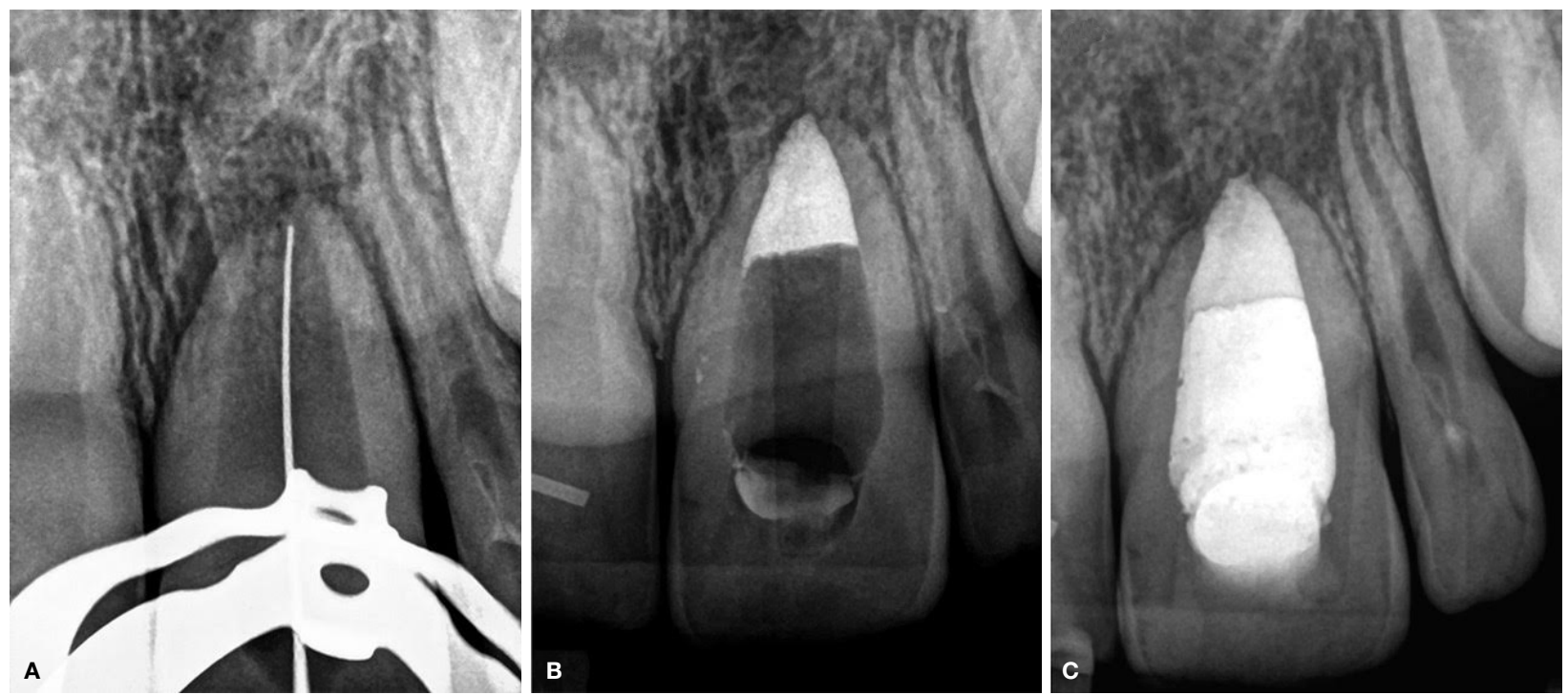

Figure 4. (A) Working length confirmation of the left central incisor on a peri-apical radiograph. Note the size of the root canal compared with that of the size $25 \mathrm{~K}$-File. (B) MTA placed in the lower $4 \mathrm{~mm}$ of the maxillary central incisor. (C) Immediate postoperative radiograph after obturation with heated gutta-percha.
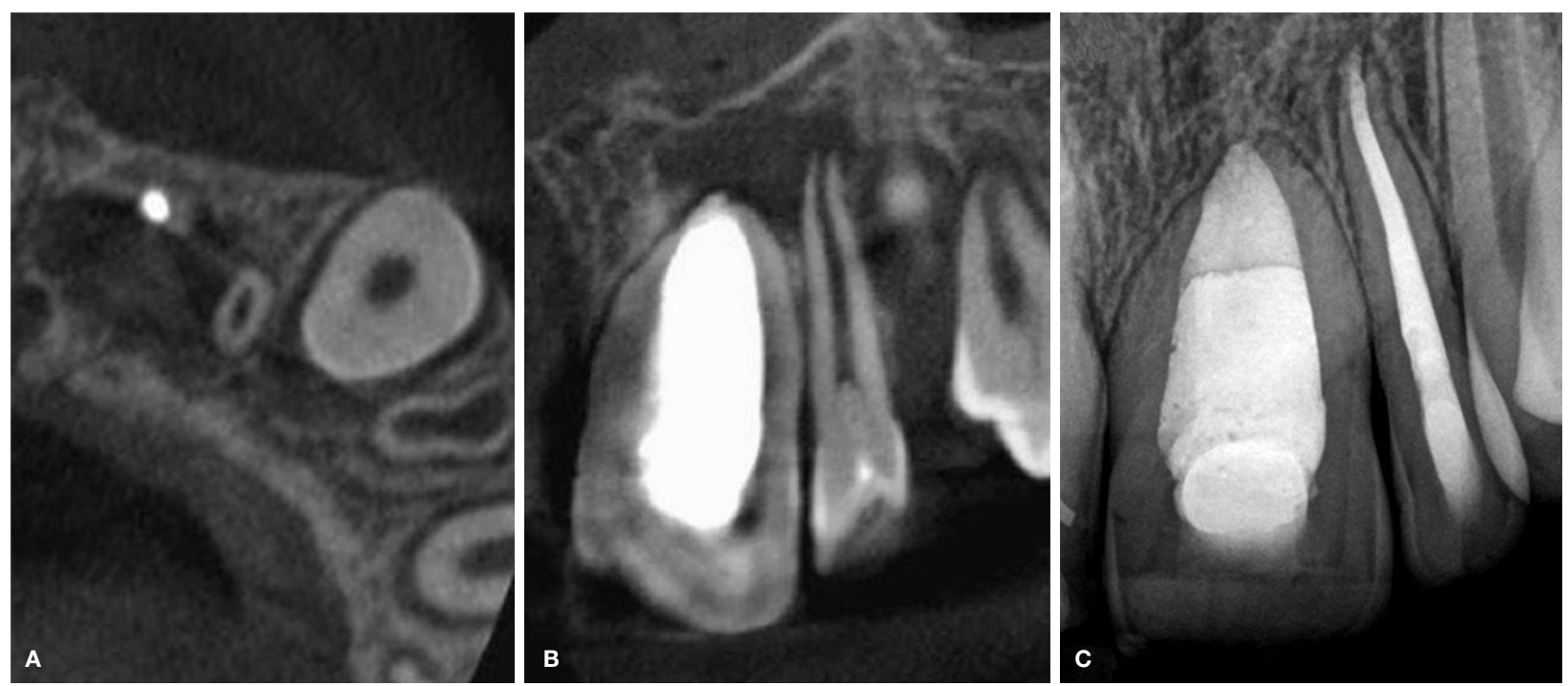

Figure 5. Limited field-of-view CBCT showing: (A) the axial view at the level of the root apex of the left maxillary lateral incisor. Note the large periapical lesion extending mesially to the obturated central incisor; (B) the coronal view confirming the large periapical lesion. (C) Postoperative 2-year follow-up radiograph confirming good healing of the periapical pathology after treatment of both teeth. 
with a fissure sealant material. The CBCT scan also showed immature root development of the left lateral incisor presenting with dens invaginatus Type II with a radiolucent area around the root tip, corresponding to the appearance of a dental follicle (Figure 3D).

The tooth was anesthetized and isolated with a rubber dam, working length was determined using a size 25 K-File (Dentsply Sirona, Charlotte, US) with an apex locator and confirmed with a peri-apical radiograph (Figure 4A). An emergency root canal was performed for pain relief. Under microscope magnification (Zumax Medical, Suzhou, China), the pulp chamber was found to be ribbon shaped and very wide mesio-distally. Calcium hydroxide (Calacept; Ultradent, South Jordan, UT, USA) was placed as an intracanal medicament.

At the second visit two weeks later, the tooth was asymptomatic and presented with no mobility. The open apex was closed by packing a $4 \mathrm{~mm}$ increment of mineral trioxide aggregate (MTA) (ProRoot MTA; Dentsply Sirona, Charlotte, US) (Figure 4B). The mineral trioxide aggregate was mixed according to the manufacturer's instructions and introduced into the canal with the MAP system (Micro-Apical Placement System) (PD Dental, Vevey, Switzerland) $0.5 \mathrm{~mm}$ short of the radiographic apex and condensed by gently packing it with an S-Kondenser (Obtura Spartan Endodontics, II, USA).

A few days later, after clinical confirmation that the MTA material was properly set (by scratching the surface of the MTA plug that was packed in the apical third of the root canal with a sharp instrument) the remainder of the root canal was obturated with heated gutta-percha delivered from an Obtura II unit (Obtura Spartan, Algonquin, IL). The access cavity was restored with a bulk fill resin (SDR; Dentsply Sirona, Charlotte, US) and composite resin material (Ceram.x Spheretec; Dentsply Sirona, Charlotte, US) (Figure 4C). The patient was scheduled for a followup visit to assess healing.

Ten months later, the patient presented for a follow-up visit. Vitality testing was performed again on the adjacent teeth, and the maxillary left lateral incisor was found to be nonvital. The follow-up, low-resolution CBCT revealed a large periapical area around the root tip of the left lateral incisor (Figures 5A-B) that presented with Type II dens invaginatus. The tooth was treated similarly to the central incisor by removing the necrotic pulp tissue and packing MTA close to the open apex of the root canal (using the same technique as described above), followed by obturation with heated gutta-percha.

A two-year, postoperative, periapical follow-up radiograph revealed complete resolution of the periapical pathology (Figure 5C).

\section{DISCUSSION}

An early diagnosis is essential for conservative treatment approaches. If no entrance to the invagination can be detected clinically and no signs of periapical pathology are visible clinically or radiographically, only regular follow up is recommended. ${ }^{11,36}$ Deep palatal or incisal invaginations or foramina coeca should be sealed before carious des- truction can occur. ${ }^{11,27}$ If the invagination is larger and pose the possibility to contain caries, it is recommended that the invagination be enlarged and explored.

Caries should be excavated, and the cavity can be decontaminated by applying chlorhexidine or sodium hypochlorite before restoring. ${ }^{27}$ Vital pulp therapy may be necessary if small communications arise during cleaning of the invaginations. ${ }^{27}$ These minimally invasive preventative treatments should be followed up regularly for the deterioration of sealants and restorations and signs and symptoms of pulp pathosis.

Root canal treatment is indicated in cases where the pulp is irreversibly inflamed or necrotic. When the invagination has a separate apical or lateral foramen, root canal treatment of the invagination can be managed as an additional canal. ${ }^{23,37}$ In some cases, eliminate minor forms of invaginations during root canal therapy is possible because they join with the main canal during instrumentation, thereby treating it as a single canal. Another option in larger invaginations is to remove the invagination within the pulp canal as a whole. ${ }^{24,38}$ Caries-indicating dye can be used to identify the outline of the dens, which is then troughed around it to loosen it. A tight-fitting file can then be screwed into the dens to aid in removal; however, this technique is not possible in all cases. $^{38}$

The large and irregular volume of the root canal system makes proper shaping and cleaning difficult. ${ }^{11}$ Irrigation supported by negative pressure and/or ultrasonic activation is recommended to achieve adequate chemomechanical cleaning of the complex morphology of the root canal system. ${ }^{38-40}$ Vertical condensation or thermoplastic filling techniques have been recommended for obturation. ${ }^{11,37}$ When pulp necrosis occurs before root-end closure, apexification procedures may be necessary, as demonstrated in this case. Pulp revascularization techniques as treatment options are still being investigated. $38,41,42$

Surgical treatment can be used with root canal therapy and can include debridement, retrograde filling of canals and apicectomy. Surgery is also considered in cases of endodontic failure and in teeth that cannot be treated nonsurgically because of anatomical problems or failure to gain access to all parts of the root canal system. ${ }^{43-45}$ Intentional extraction and replantation with retrograde surgery in otherwise hopeless cases has also been suggested. Extraction is only indicated for supernumerary teeth or teeth with severe anatomical irregularities that cannot be treated nonsurgically or by apical surgery. ${ }^{11}$

\section{CONCLUSION}

Dental anomalies often occur together, and it is advised to always investigate all teeth if an anomaly is diagnosed. An early diagnosis is essential to allow preventative and minimally invasive treatment approaches.

The complexity of the anomaly, pulp status and amount of tooth structure available will determine the correct choice of treatment. For longterm success, the aim of the management of macrodontia and dens invaginatus anomalies must be to prevent or eliminate infection, maintain tooth structure and restore aesthetics and function. 


\section{Declaration of interests}

The authors declare no conflict of interest.

\section{References}

1. Nanci A. Ten Cate's Oral Histology: Development, structure, and function. $8^{\text {th }}$ ed. St Louis, MO: Mosby Elsevier; 2013; 5: 70-94.

2. Rohilla M. Aetiology of various dental developmental anomalies - review of literature. J Dent Probl Solut. 2017; 4(2): 19-25.

3. Gopalakrishna A, Kumar M, Venugopal D, Sunil A, Jaleel D, Venugopal V. Macrodont Molariform Premolars: A Rare Entity. Oral Max Path J. 2018; 9(1): 36-41.

4. Cardona NR, Tapias JJ, Henao JMC. Mandibular bilateral macrodontia and hyperdontia: a clinical case report. Rev Fac Odontol Univ Antioq. 2011; 23(1): 177-81.

5. Shafer W, Hine M, Levy B. A textbook of oral pathology. $4^{\text {th }}$ ed. WB Saunders USA. 1983.

6. Pereira L, de Almeida Assunção P, de Almeida Salazar SL, Guedes FR, Abrahão AC, Cabral MG, et al. Uncommon true isolated macrodontia of a maxillary tooth. J Contemp Dent Prac. 2014; 15(1): 116.

7. Groper JN. Macrodontia of a single tooth: review of literature and report of case. J Am Dent Assoc. 1987; 114(1): 69.

8. Hellekant M, Twetman S, Carlsson L. Treatment of a Class II Division 1 malocclusion with macrodontia of the maxillary central incisors. Am J Orthod Dentofac Orthop. 2001; 119(6): 654-9.

9. Šutalo J, Kneževic A, Negovetic-Mandic V. Endodontic Treatment of Dens Invaginatus-Case Report. Acta Stomatol Croat. 2004; 38(2): 215-8.

10. Hunter $H$. Dilated composite odontome: reports of two cases, one bilateral and one radicular. Oral Surg Oral Med Oral Pathol. 1951; 4(5): 668-73.

11. Hülsmann M. Dens invaginatus: aetiology, classification, prevalence, diagnosis, and treatment considerations. Int Endod J. 1997; 30(2): 79-90.

12. Atkinson SR. The permanent maxillary lateral incisor. Am J Orthod Oral Surg. 1943; 29(12): 685-98.

13. Swanson W, McCarthy Jr F. Bilateral dens in dente. J Dent Res. 1947; 26(2): 167-71.

14. Casamassimo PS, Nowak AJ, Ettinger RL, Schlenker DJ. An unusual triad: microdontia, taurodontia, and dens invaginatus. Oral Surg Oral Med Oral Pathol. 1978; 45(1): 107-12.

15. Ekman-Westborg B, Julin P. Multiple anomalies in dental morphology: Macrodontia, multituberculism, central cusps, and pulp invaginations: Report of a case. Oral Surg Oral Med Oral Pathol. 1974; 38(2): 217-22.

16. Hosey MT, Bedi R. Multiple dens invaginatus in two brothers. Dent Traumatol. 1996; 12(1): 44-7.

17. Kronfeld R. Dens in dente. J Dent Res. 1934; 14(1): 49-66.

18. Oehlers F. Dens invaginatus (dilated composite odontome): I. Variations of the invagination process and associated anterior crown forms. Oral Surg Oral Med Oral Pathol. 1957; 10(11): 1204-18.

19. Bruszt P. Aetiology of dens in dente. Schweizz Monatsschr Zahnheilkd. 1950; 60(6): 534.

20. Rushton MA. A collection of dilated composite odontomes. Brit Dent J. 1937; 63: 65-86.

21. Sprawson E. Odontome: a brief overview. Br Dent J. 1937; 62: 177-201.

22. De Sousa S, Bramante C. Dens invaginatus: treatment choices. Dent Traumatol. 1998; 14(4): 152-8.

23. Khabbaz M, Konstantaki M, Sykaras S. Dens invaginatus in a mandibular lateral incisor. Int Endod J. 1995; 28(6): 303-5.

24. Girsch WJ, McClammy TV. Microscopic removal of dens invaginatus. J Endod. 2002; 28(4): 336-9.

25. Ridell K, Mejare I, Matsson L. Dens invaginatus: a retrospective study of prophylactic invagination treatment. Int J Paediatr Dent. 2001;11(2): 92-7.
26. Alani A, Bishop K. Dens invaginatus. Part 1: classification, prevalence and aetiology. Int Endod J. 2008; 41(12): 1123-36.

27. Bishop K, Alani A. Dens invaginatus. Part 2: clinical, radiographic features and management options. Int Endod J. 2008; 41(12): 1137-54.

28. Parnell A, Wilcox J. Frequency of palatal invagination in permanent maxillary anterior teeth. ASDC J Dent Child. 1978; 45(5): 392.

29. Gotoh T, Kawahara K, Imai K, Kishi K, Fujiki Y. Clinical and radiographic study of dens invaginatus. Oral Surg Oral Med Oral Pathol. 1979; 48(1): 88-91.

30. Goaz PW, White SC. Oral radiology: principles and interpretation: Mosby Louis; 1994.

31. Gonçalves A, Gonçalves M, Oliveira D, Goncalves N. Dens invaginatus type III: report of a case and 10-year radiographic follow-up. Int Endod J. 2002; 35(10): 873-9.

32. Hallett $G$. The incidence, nature, and clinical significance of palatal invaginations in the maxillary incisor teeth. SAGE Publications; 1953: 491-9.

33. Schulze C, Brand E. Dens invaginatus (dens in dente). ZWR. 1972; 81(15): 699-703.

34. Martins JN, da Costa RP, Anderson C, Quaresma SA, CorteReal LS, Monroe AD. Endodontic management of dens invaginatus Type IIIb: Case series. Eur J Dent. 2016; 10(4): 561.

35. Sisodia N, Manjunath M. Double dens in dente: a rare anomaly. S Afr Dent J. 2016; 71(9): 410-1.

36. Duckmanton P. Maxillary permanent central incisor with abnormal crown size and dens invaginatus: case report. Dent Traumatol. 1995; 11(3): 150-2.

37. Mangani F, Ruddle CJ. Endodontic treatment of a "very particular" maxillary central incisor. J Endod. 1994; 20(11): 560-1.

38. Narayana P, Hartwell GR, Wallace R, Nair UP. Endodontic clinical management of a dens invaginatus case by using a unique treatment approach: a case report. J Endod. 2012; 38(8): 1145-8.

39. Cunningham WT, Martin H, Pelleu Jr GB, Stoops DE. A comparison of antimicrobial effectiveness of endosonic and hand root canal therapy. Oral Surg Oral Med Oral Pathol. 1982; 54(2): 238-41.

40. Skoner JR, Wallace JA. Dens invaginatus: another use for the ultrasonic. J Endod. 1994; 20(3): 138-40.

41. Banchs F, Trope M. Revascularization of immature permanent teeth with apical periodontitis: new treatment protocol? J Endod. 2004; 30(4): 196-200.

42. Huang GJ. Apexification: the beginning of its end. Int Endod J. 2009; 42(10): 855-66.

43. Lindner C, Messer $\mathrm{H}$, Tyas M. A complex treatment of dens invaginatus. Dent Traumatol. 1995; 11(3): 153-5.

44. Rotstein I, Stabholz A, Heling I, Friedman S. Clinical considerations in the treatment of dens invaginatus. Dent Traumatol. 1987; 3(5): 249-54.

45. Cole GM, Taintor JF, James GA. Endodontic therapy of a dilated dens invaginatus. J Endod. 1978; 4(3): 88-90. 